\title{
Search Diversion and Platform Competition
}

\section{Citation}

Hagiu, Andrei, and Bruno Jullien. "Search Diversion and Platform Competition." International Journal of Industrial Organization 33 (March 2014): 48-60.

\section{Published Version}

http://www.sciencedirect.com/science/article/pii/S0167718714000216

\section{Permanent link}

http://nrs.harvard.edu/urn-3:HUL.InstRepos:14358171

\section{Terms of Use}

This article was downloaded from Harvard University's DASH repository, and is made available under the terms and conditions applicable to Open Access Policy Articles, as set forth at http:// nrs.harvard.edu/urn-3:HUL.InstRepos:dash.current.terms-of-use\#OAP

\section{Share Your Story}

The Harvard community has made this article openly available.

Please share how this access benefits you. Submit a story.

Accessibility 


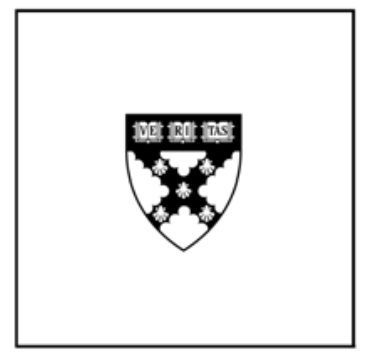

\title{
Search Diversion and Platform Competition
}

\author{
Andrei Hagiu \\ Bruno Jullien
}

\section{Working Paper}

$11-124$

February 18, 2014 


\title{
Search Diversion and Platform Competition*
}

\author{
Andrei Hagiu ${ }^{\dagger}$ and Bruno Jullien ${ }^{\ddagger}$
}

February 2014

\begin{abstract}
Platforms use search diversion in order to trade off total consumer traffic for higher revenues derived by exposing consumers to unsolicited products (e.g. advertising). We show that competition between platforms leads to lower equilibrium levels of search diversion relative to a monopoly platform when the intensity of competition is high. On the other hand, if there is only mild competition, then competing platforms induce more search diversion relative to a platform monopolist.

When platforms charge consumers fixed access fees, all equilibrium levels of search diversion under platform competition are equal to the monopoly level, irrespective of the nature of competition. Furthermore, relative to platforms that cannot charge such fees, platforms that charge positive (negative) access fees to consumers have weaker (stronger) incentives to divert search.
\end{abstract}

\footnotetext{
${ }^{*}$ We are grateful to Ramon Casadesus-Masanell, David Henriques, Joao Montez, Volker Nocke and participants at the CRES Foundations of Business Strategy Conference (Olin Business School, Washington University in Saint Louis), CRESSE (Greece) and at the Third Annual Conference on Internet Search and Innovation (Northwestern Law School) for very helpful comments and feedback on a previous draft.

${ }^{\dagger}$ Harvard University (HBS Strategy Unit), ahagiu@hbs.edu

¥Toulouse School of Economics (IDEI \& GREMAQ), bjullien@cict.fr
} 


\section{Introduction}

Search diversion occurs when platforms providing access to various products deliberately introduce noise in the search or browsing process through which consumers find the products they are most interested in. This practice is widespread among both offline and online platforms. All advertising-supported media (from magazines to online portals, news sites, and search engines) are purposefully designed to expose users to advertisements, even though they are primarily interested in content. Similarly, retailers often place the most sought-after items at the back or upper floors of their stores (e.g. bread and milk at supermarkets, iPods and iPhones at Apple stores), while shopping malls design their layout to maximize the distance travelled by visitors between anchor stores (Petroski 2003). E-commerce sites (e.g. Amazon, Bing Shopping, eBay, Google Shopping) design their websites in order to divert users' attention away from the products they were initially looking for, and towards the discovery of products that they might be interested in and eventually buy (unsolicited products or advertising).

On the one hand, search diversion may lead to higher platform revenues per consumer "visit" to the platform. On the other hand, it reduces the overall attractiveness of the platform to consumers and therefore also leads to lower consumer traffic (i.e. total number of visits). All platforms listed above face this fundamental trade-off.

The basic economic logic of search diversion was first analyzed by Hagiu and Jullien (2011), using a model with a monopoly platform (intermediary) that offers consumers access to two products, whose affiliation with (i.e. availability through) the platform is exogenously given. Here we extend that analysis by adding two important elements: (i) platform competition and (ii) endogenous affiliation on both sides of the market - consumers and an unsolicited product supplier (advertiser).

Our main result is that when consumers affiliate exclusively with one platform, competition does not necessarily reduce search diversion incentives relative to monopoly. Specifically, if competition between platforms is intense (low degree of differentiation) then competing platforms induce less search diversion than a monopolist. But when competition is of moderate intensity (intermediate degree of differentiation), search diversion is greater than in the case of a monopoly platform. Finally, if the degree of platform differentiation is large then competing 
platforms behave like local monopolies and therefore choose the monopoly level of search diversion. One interpretation of the scenario in which competing platforms divert search more than a monopoly is that, since consumers are more difficult to attract under competition, platforms may prefer to increase revenue per consumer by diverting more search. This result holds whether the advertiser affiliates exclusively or multihomes. Moreover, with exclusive advertising affiliation, each platform takes into account its competitor's incentives to compete for the advertiser. As a result, when competition is effective on both sides, the equilibrium level of search diversion maximizes total industry profit (both platforms and the advertiser). On the other hand, one platform may prefer not to compete for the advertiser if it derives sufficient consumer demand and revenue from the content solicited by consumers. In this case, the equilibrium level of search diversion does not account for the "losing" platform's profits.

Second, allowing platforms to charge fixed access fees results in less search diversion if and only if the actual fee charged is positive. Furthermore, if platforms can charge consumers access fees, competing platforms choose the same level of search diversion as a monopoly platform for all parameter values and regardless of the mode of platform competition: all platforms maximize the total surplus per consumer.

The remainder of the paper is organized as follows. In the next two subsections we provide a brief overview of our model and of the relevant literature. Section 2 lays out the modeling set-up and analyzes the monopoly platform case, with endogenous consumer and advertising affiliation. Section 3 introduces competition between platforms and analyzes three scenarios: a) platforms compete for the exclusive affiliation of consumers, whereas the advertiser multihomes; b) platforms compete for the exclusive affiliation of the advertiser, whereas consumers multihome; c) platforms compete for the exclusive affiliation of both consumers and the advertiser. In section 4 we introduce the possibility for platforms to charge consumers access fees. Section 5 concludes. 


\subsection{Model overview and interpretation}

In our model, each platform offers consumers access to two products, 1 and 2. Product 1 (content) offers consumers expected utility $u_{1}>0$ and is assumed to be exogenously affiliated with each platform throughout the paper. Product 2 corresponds to unsolicited content, which for convenience we refer to as advertising. It offers consumers expected utility $u_{2}=0$ and is supplied by a third-party seller (advertiser), who must be induced to affiliate by platforms' choices of fees and search diversion. Platforms may derive positive revenues from consumer exposure to both products. Each product exposure is costly to consumers: it requires time and attention. The platforms' revenues per consumer exposure to product $1\left(\pi_{1}\right)$ could be referral fees paid by an independent seller or the margin made on the sale of product 1 multiplied by the conversion rate (probability that a consumer who sees the product ends up buying it) if the platform supplies product 1 itself; or any type of fees directly tied to usage of product 1 (e.g. pay-per-view). Meanwhile, the platforms' revenues per consumer exposure to product $2\left(\pi_{2}\right)$ can be interpreted as "per-impression" or "per-click" fees paid by its seller.

The key decision made by the platform is the amount of search diversion to induce through its service, which we identify with the probability that it exposes consumers to product 2 before directing them to product 1. Indeed, although consumers always prefer being immediately exposed to product 1, the platform may find that first diverting them to product 2 maximizes total revenues. We use the term "search" because in a sense consumers are searching for product 1 and the platform chooses how efficient to make this search process. More search diversion leads to higher total exposure costs incurred by consumers. 


\begin{tabular}{|c|c|c|c|c|c|}
\hline Platform & Product 1 & Product 2 & $\pi_{1}$ & $\pi_{2}$ & Access fee? \\
\hline $\begin{array}{l}\text { Search engines } \\
\text { (e.g. Bing, Google) }\end{array}$ & $\begin{array}{l}\text { Organic search } \\
\text { results }\end{array}$ & $\begin{array}{l}\text { Sponsored search } \\
\text { results }\end{array}$ & $=0$ & $\begin{array}{l}\text { Advertising fees } \\
\text { (mostly CPC) }\end{array}$ & No \\
\hline $\begin{array}{l}\text { Shopping portals } \\
\text { (e.g. Bing Shopping, } \\
\text { Google Shopping, } \\
\text { Yahoo Shopping) }\end{array}$ & $\begin{array}{l}\text { Products or } \\
\text { information user is } \\
\text { looking for }\end{array}$ & $\begin{array}{l}\text { Other products } \\
\text { advertised on the } \\
\text { page }\end{array}$ & $\begin{array}{l}\quad>0 \\
\text { (referral fees paid by } \\
3^{\text {rd }} \text { party merchants of } \\
\text { products listed) }\end{array}$ & Advertising fees & No \\
\hline $\begin{array}{l}\text { Content portals } \\
\text { (e.g. Forbes, New } \\
\text { York Times, Yahoo) }\end{array}$ & Editorial content & $\begin{array}{l}\text { Display } \\
\text { advertising }\end{array}$ & $=0$ & $\begin{array}{l}\text { Advertising fees } \\
\text { (CPM and CPC) }\end{array}$ & $\begin{array}{l}\text { Yes (NYT) } \\
\text { No (Forbes, } \\
\text { MSN, Yahoo) }\end{array}$ \\
\hline $\begin{array}{l}\text { Online video portals } \\
\text { (e.g. Hulu, Vimeo, } \\
\text { YouTube) }\end{array}$ & Video content & $\begin{array}{l}\text { In-video } \\
\text { advertising }\end{array}$ & $\begin{array}{c}\quad=0 \text { (YouTube) } \\
>0 \text { (Hulu, Vimeo: } \\
\text { video-on-demand fees) }\end{array}$ & $\begin{array}{l}\text { In-video } \\
\text { advertising fees }\end{array}$ & $\begin{array}{l}\text { Yes (Hulu Plus) } \\
\text { No (YouTube) }\end{array}$ \\
\hline $\begin{array}{l}\text { E-commerce sites } \\
\text { (e.g. Fandango, } \\
\text { Zappos) }\end{array}$ & $\begin{array}{l}\text { Products or } \\
\text { information user is } \\
\text { looking for (e.g. } \\
\text { movie schedules; } \\
\text { shoe descriptions) }\end{array}$ & $\begin{array}{l}\text { Display } \\
\text { advertising }\end{array}$ & $\begin{array}{l}\qquad>0 \\
\text { (booking fees paid by } \\
\text { users buying movie } \\
\text { tickets or margins } \\
\text { made on shoes sold) }\end{array}$ & Advertising fees & No \\
\hline
\end{tabular}

Table 1

Our modelling set-up is best interpreted as a stylized representation of advertising-supported media, such as the ones listed in Table $1 .^{1}$ All platforms listed in Table 1 provide users with first-party content (cf. Hagiu and Spulber 2012), such as organic search results, information, editorial stories or products sold in their own name. All of them make positive revenues from user exposure to advertising or products users were not necessarily looking for $\left(\pi_{2}>0\right)$. Some of them (search engines, content portals) make no revenues from first-party content, while others (shopping portals, e-commerce and paid video sites) derive positive revenues from exposing consumers to first-party content. For shopping portals, $\pi_{1}$ is equal to the click-through rate of listed products multiplied by the referral fees charged to the third-party merchants who sell those products. For online video sites and e-commerce, $\pi_{1}$ is the conversion rate multiplied by the video-on-demand prices (Hulu, Vimeo) or the booking fees charged to users (Fandango) or the margins made on shoes sold (Zappos).

The extent of search diversion varies across these platforms from minimal (small and unin-

\footnotetext{
${ }^{1} \mathrm{CPM}$ is the advertising industry term for cost per impression (literally, "cost per mille", i.e. a thousand impressions), while CPC stands for "cost per click".
} 
trusive ads on Fandango.com, sponsored search results at the bottom of Google Shopping pages) to moderate (sponsored search results at the top and right-hand side of Google's search engine pages) to very high (in addition to showing several large ads on every content page, Forbes.com requires users to view a video ad prior to watching every piece of video content and oftentimes to click through a full-page display ad before reaching the desired content page).

\subsection{Related literature}

Our paper builds upon the model of search diversion introduced by Hagiu and Jullien (2011). That paper established that search diversion allows platforms to: (i) trade off higher total consumer traffic for higher revenues per consumer visit; and (ii) influence independent product sellers' choices of strategic variables (e.g., pricing). It also showed that search diversion is a strategic instrument that cannot be easily replaced by contractual extensions and that it can be socially desirable because consumers do not internalize the benefits of their search activities for product sellers. We extend Hagiu and Jullien (2011)'s analysis in two important and novel directions: competition among platforms and endogenous product and consumer affiliation (Hagiu and Jullien 2011 focus exclusively on a monopoly platform with exogenously given product and consumer affiliation).

We contribute to the economics and strategy literature on two-sided platforms by introducing a key design decision that many platforms have to make, but has not been formally studied: search diversion. Indeed, most of the existing work on two-sided platforms focuses on pricing strategies (Armstrong 2006, Parker and Van Alstyne 2005, Rochet and Tirole 2006, Weyl 2010) and market outcomes (Caillaud and Jullien 2003, Hossain et al. 2011) in the presence of indirect network effects. Our paper is aligned with an emerging body of work aiming to expand the formal study of platforms to design decisions (e.g. Parker and Van Alstyne 2008, Boudreau 2010, Hagiu and Spulber 2012, Veiga and Weyl 2012).

At a broader level, several articles have pointed out that platforms have to make design compromises between the interests of their two sides (e.g. Kaplan and Sawhney 2000, Evans and Schmalensee 2007), but this issue has received limited formal modelling treatment. An exception is the recent literature on search engines. Eliaz and Spiegler (2011) show that vertical 
search engines do not necessarily maximize consumer search quality, a point similar to Hagiu and Jullien (2011), though in a different context. Relatedly, Yang and Ghose (2010), Taylor (2013) and White (2013) emphasize that raising the quality of search results may cannibalize revenue from sponsored links, while Burguet et al. (2013) study the joint choice of match quality for the organic and sponsored links displayed. Our model here is different in that we focus on advertising that negatively impacts the perceived quality of the search service by consumers.

Finally, our paper is also connected to the literature on advertising-supported platforms: Anderson and Coate (2005), Gabszewicz et al. (2006), Peitz and Valletti (2008), Crampes et al. (2009), Ellman and Germano (2009), Casadesus-Masanell and Zhu (2010). In particular, Ellman and Germano (2009) consider a newspaper model where the quality of news reporting matters for readers but also for (non-intrusive) advertising effectiveness. They find that newspaper competition has an ambiguous effect on news quality. These papers study product positioning and product quality choices by ad-sponsored platforms. In contrast, our focus is on the design of platforms' product exposure mechanism.

A very recent strand of this literature studies the effect of consumers' and advertisers' "multihoming" behavior (i.e. their presence on multiple online outlets) on firm profits. Athey Calvano and Gans (2012) show that the value of advertising in one outlet depends on consumer multihoming and focus on tracking technologies, while Athey and Gans (2010) study targeted advertising. In our competition sections, we analyze the impact of consumer and advertiser multihoming on the endogenous rate of exposure to advertising (search diversion in our model). Ambrus, Calvano and Reisinger (2012) discuss the nature of price competition when all agents can multihome. We share with them the conclusion that competition does not restore efficiency, but their paper focuses on the volume of advertising, whereas we focus on the design of the exposure service. Broadly, targeting, tracking and diversion can all be viewed as various instances of platform service design, thus our work is complementary to this stream of literature. 


\section{Monopoly platform set-up}

In this section we lay out the foundation for our analysis using a variant of the model in Hagiu and Jullien (2011). We present the model here but postpone its discussion until after proposition 1, where it will be more transparent. There is a monopoly platform which allows a unit mass of consumers to access two products, 1 and 2. Product 1 is already available through (or affiliated with) the platform, while product 2 must be attracted by the platform (its affiliation is endogenous). To access either product, a consumer must first affiliate with (i.e. visit) the platform and then be exposed to the product through a search process described below. Consumers are interested in product 1 only, which can be interpreted as content, e.g. editorial stories, videos, organic search results. They are not interested in product 2 , which can be interpreted as advertising.

\subsection{Consumers}

All consumers derive net expected utility $u_{1}=u$ from being exposed to product 1 and $u_{2}=0$ from being exposed to product 2 , where $0<u<1$ is exogenously given. These utilities should be interpreted as encompassing the utility of just viewing the product plus the expected utility of actually consuming it, net of the price paid (we do not model product pricing decisions).

Ex-ante, i.e. before affiliating with the platform, consumers only differ in their location $x$, uniformly distributed on $[0,1]$. The monopoly platform is located at 0 . When consumer $x$ affiliates with the platform, she incurs transportation costs $t x$, where $t>0$.

Ex-post, i.e. after deciding whether or not to affiliate with the platform, consumers learn their unitary cost of exposure (or cost of search) $c$, which they incur whenever they are exposed to a product. When both products are affiliated with the platform, consumers can only view them sequentially and therefore are subject to one or two product exposures. The search cost $c$ can be interpreted as the cost of consumer attention; it is distributed on $[0,1]$ according to a twice continuously differentiable cumulative distribution function $F$. From an ex-ante perspective, a consumer located at any position $x$ perceives the same ex-post distribution of search costs $F($.$) .$ 
Thus, consumers make two decisions: whether or not to visit the platform, and whether or not to engage in product search if they decided to visit the platform.

\subsection{The platform}

For conciseness, we assume that the monopoly platform is vertically integrated into product 1 . The platform derives expected profits $\pi_{1} \geq 0$ for each consumer exposure to product 1 , where $\pi_{1}$ is known by all players and exogenously fixed.

Product 2 is supplied by an independent seller (advertiser), who must be induced to affiliate. The advertiser derives profit $\pi_{2}$ for every consumer exposure to its product, which is also publicly known (we study the case in which $\pi_{2}$ is unobservable in section ??). In order to affiliate with the platform and gain access to its consumers, the advertiser must pay the platform a perimpression (per-click) fee $r$. We assume the platform has all the bargaining power when setting $r$.

Throughout the paper, only the ratio $\pi_{2} / \pi_{1}$ affects the level of search diversion. For this reason, we normalize our model by setting

$$
\pi_{1}=1 \text { and } \pi_{2}=\pi .
$$

Note that a platform with no revenue from first-party content $\left(\pi_{1}=0\right)$ corresponds to $\pi=+\infty$, which can be accommodated by the analysis.

For now, we assume the platform does not charge any access fees to consumers. We study the effect of allowing access fees in section 4 .

\subsection{Search diversion}

The platform has a design technology that allows it to choose a probability $s \in[0,1]$ with which it first exposes any given consumer to product 2 before showing her product 1 . The probability $s$ represents the level of search diversion induced by the platform. Once a consumer has been exposed to product 2 , she knows that she will next be exposed for sure to product 1 , but she 
will then need to incur her search cost $c$ again. The focus of our paper is on platforms' choice of $s$. We assume that $s$ can be costlessly set to any value between 0 and 1 .

One can think of $(1-s)$ as a measure of how efficient the design of the platform is for consumers. Does the platform provide quick and clear access to the products or content that consumers are searching for (low $s)$ ? Or does it try to expose consumers to various forms of unsolicited content before providing the service they came for in the first place (high $s$ )?

\subsection{Timing}

The timing of the game we consider in this section is as follows:

1. The platform commits to $s$ publicly and credibly

2. The platform sets the fee $r$ to be paid by the advertiser

3. The advertiser decides whether or not to affiliate with the platform

4. Consumers observe $s$ and the advertiser's affiliation decision and decide whether or not to affiliate with the platform

5. Affiliated consumers learn their individual cost $c$, then engage in product search.

Three aspects of this set-up deserve mention. First, separating the choices of $s$ and $r$ has no effect on the solution of the monopoly game.

Second, the design parameter $s$ is observed by consumers before deciding whether or not to visit the platform (for instance, through reviews or word of mouth) and by the advertiser before deciding to affiliate or not, and we assume it is not subject to ex-post opportunism, i.e. cannot be adjusted once affiliation decisions have been made. In fact, it is in the platform's best interest to credibly announce $s$ upfront because $s$ affects not only consumer utility, but also expected payoffs for the advertiser that the platform is courting. ${ }^{2}$

\footnotetext{
${ }^{2}$ If ex-post opportunism was possible, then the unique equilibrium with consistent expectations would be $s^{*}=1$. Indeed, once consumers and the advertisers are affiliated, the platform can unambiguously increase revenues by increasing $s$. Thus, it is in the platform's interest to credibly commit to (or develop a reputation for) a level of search diversion $s^{*}<1$ ex-ante $\left(s^{*}=1\right.$ is almost never optimal).
} 
Third, affiliation decisions by consumers typically involve longer time horizons than activity (search) decisions. Moreover, affiliation is usually based on less information than activity, as consumers learn about the platform gradually. This is captured by our assumption that affiliation is based on the level of search diversion and expectation of search costs, while activity (search) is based on the realized individual search cost. This assumption simplifies the analysis without loss of substance: the key feature that we need is that total consumer demand is decreasing in $s$ (as is realistic).

\subsection{The consumer search process and affiliation decision}

In stage 5, consumers affiliated with the platform must decide whether to search or not. When the platform has chosen $s>0$ and product 2 is affiliated, consumers know that they may be diverted. A consumer with search cost $c \leq u$ who is first diverted to product 2 will still proceed to product 1 , because she knows with certainty that she will obtain net utility $u-c \geq 0$. If the consumer is not diverted, i.e. if she is directly exposed to product 1, then she stops searching immediately and will not be exposed to product 2 (which would yield negative net utility $-c$ ). To fix ideas, it is useful to think of an advertising-supported news website. If a user is first shown an ad, she will still click or scroll to find the news content. If she is shown the content right away, she will never go on searching for ads.

The consumer's net expected utility from searching is thus $u-(1+s) c$ and is positive for $c \leq u /(1+s)$. Consumers with search cost above $u /(1+s)$ do not engage in search at all. Using the news website example, the expected utility provided by the site to such consumers is not sufficient to justify the time wasted clicking through or scrolling over ads.

Working backwards to stage 4 , a consumer located at $x$ affiliates with the platform if and only if $V(s)-t x \geq 0$, where:

$$
V(s) \equiv \int_{0}^{u /(1+s)}(u-(1+s) c) f(c) d c
$$

is the expected consumer utility from the perspective of stage 4, gross of access price and transportation costs. Note that $V(s)$ is decreasing. 
If only one product is affiliated with the platform then consumers who visit the platform find the affiliated product with probability 1 in just one round of search. If only product 1 is affiliated then expected consumer utility from the perspective of stage 4 is $V(0)$. If only product 2 is affiliated then expected consumer utility is 0 .

\subsection{Optimal search diversion}

Since the advertiser's per impression profit $\pi$ is common knowledge, the platform sets $r=\pi$ (slightly below) in stage 2 , which ensures the advertiser affiliates and extracts its entire profit. ${ }^{3}$ The incentives to divert search are thus the same as if the platform were also vertically integrated with the product 2 seller, i.e. if it owned both products.

Total consumer demand for (or traffic to) the platform is then $\min (V(s) / t, 1$ ), weakly decreasing in the level of search diversion $s$. The platform's profits as a function of $s$ are

$$
X(s, \pi) \min (V(s) / t, 1),
$$

where we have denoted ${ }^{4}$

$$
X(s, \pi) \equiv(1+s \pi) F\left(\frac{u}{1+s}\right)
$$

the revenues derived by the platform from the product exposures of each affiliated consumer.

The optimization of (2) over $s$ involves a trade-off between total consumer traffic and participation in the search process on the one hand, and the average number of product exposures per consumer on the other hand. Indeed, an increase in $s$ induces a consumer to see two products with probability $s$, which yields revenues $1+s \pi$ to the platform, but it also reduces the proportion of consumers who engage in search, $F(u /(1+s))$, as well as total consumer traffic to the platform, $V(s) / t$. Variations of this trade-off are analyzed at length in Hagiu and Jullien (2011). The key novelty here is the term $V(s) / t$ : indeed, Hagiu and Jullien (2011) treat total consumer affiliation with the platform as exogenously given, equal to 1 .

\footnotetext{
${ }^{3}$ Note that the platform always (weakly) prefers to attract the advertiser. Indeed, the platform can always replicate the scenario with no advertiser affilation by choosing $s=0$.

${ }^{4}$ The argument $\pi$ is included for consistency with the competition section, where the price per exposure charged to the advertiser can be lower than $\pi$.
} 
We also denote:

$$
\begin{aligned}
s_{X V}(\pi) & \equiv \arg \max _{s}\{X(s, \pi) V(s)\} \\
s_{X}(\pi) & \equiv \arg \max _{s}\{X(s, \pi)\},
\end{aligned}
$$

so that $s_{X}(\pi)>s_{X V}(\pi)$ because $V($.$) is decreasing. With this notation, we obtain:$

Proposition 1 The optimal level of search diversion for a monopoly platform is:

$$
\begin{aligned}
s^{M}(\pi, t) & =\arg \max _{s}\{X(s, \pi) \min (V(s) / t, 1)\} \\
& =\left\{\begin{array}{ccc}
s_{X}(\pi) & \text { if } & t \leq V\left(s_{X}(\pi)\right) \\
V^{-1}(t) & \text { if } & t \in\left[V\left(s_{X}(\pi)\right), V\left(s_{X V}(\pi)\right)\right] \\
s_{X V}(\pi) & \text { if } & t \geq V\left(s_{X V}(\pi)\right)
\end{array}\right.
\end{aligned}
$$

It is (weakly) increasing in $\pi$ and (weakly) decreasing in $t$.

The second part of the proposition (proven in the appendix) states that the platform diverts search more when it derives higher revenues from the product that consumers are not interested in (advertising) relative to the product that they are interested in (content). The reason is straightforward: when the platform derives more revenues from content (advertising), its interests are more (less) aligned with those of consumers, therefore the optimal level of search diversion is lower (higher). Recall indeed that consumers always prefer less search diversion. The comparative static in $t$ is easily understood: the platform diverts search more when consumer traffic is less elastic in (i.e. less responsive to) search diversion.

This result is consistent with the examples discussed in the introduction. Restricting attention to platforms that do not charge access fees, those platforms that derive no revenues from content, i.e. with $\pi=+\infty$ (e.g. search engines, Forbes.com), clearly engage in more search diversion relative to platforms with content revenue, i.e. with $\pi$ finite (e.g. Google Shopping, Fandango). Note in particular the contrast between Google search, on which sponsored search 
results are at the top and on the right hand side of the page, and Google Shopping, where sponsored search results only appear at the bottom of the page (much less intrusive).

Thus, although highly stylized, our model contains the two ingredients necessary to capture the key trade-offs associated with search diversion. First, platforms' profit incentives are imperfectly aligned with consumer preferences: platforms derive positive revenues from exposing consumers to products that they do not care about $(\pi>0$ and possibly $\pi>1)$. Second, exposure to individual products is costly for consumers and the platform can make design decisions (captured by $s$ ) that influence the degree to which consumers are exposed to one product relative to the other.

Of course, in most real-world settings there are more than two products, multiple sellers or advertisers per product and perhaps even complementarity or substitutability across products. Introducing any of these aspects would unnecessarily complicate our analysis, since the fundamental mechanics of search diversion remain unchanged. For the same reason, we treat $\pi$ as exogenously given in our model, i.e. we do not endogenize price-setting by independent sellers. Some of these extensions are treated by Hagiu and Jullien (2011) in the context of a monopoly platform choosing search diversion. Finally, while the assumption $u_{2}=0$ best fits contexts in which product 2 is advertising (as in the examples listed in Table 1 above), the general implications we derive hold for any platforms that have incentives to divert consumers away from the products that best suit their preferences and towards products they are less but still positively - interested in $\left(u_{2}>0\right)$. For instance, Netflix uses its recommender system in an attempt to steer users towards less popular movies, which entail lower licensing costs and are less likely to run out of stock, which in turn means they generate higher margins for Netflix (Shih et al. 2007). A similar practice is used by Amazon.com. Indeed, the difference between diverting consumers to advertising and diverting them to products that they find less desirable is simply one of degree. Consumers may derive 0 expected utility from being exposed to advertisements, whereas they might perceive a (small) positive expected utility from being exposed to products other than the ones that they initially came to the platform for. The only thing that matters is that the platform derives positive margins from such unsolicited products. In a previous draft version, we worked with $u_{2}>0$ : the analysis turned out to be more complex 
than the one presented here but the main results were the same. This is why we have opted to work with $u_{2}=0$.

\section{Competition}

In this section we analyse how competition affects search diversion incentives. We maintain the same structure of consumer preferences, except that there are now two competing platforms, A and $\mathrm{B}$, one at each end of the Hotelling $[0,1]$ segment. Each platform is vertically integrated into product 1 . Although we use the same label, product 1 on platform $A$ may differ from the product 1 on platform B. We consider three competition scenarios:

i) Competition for consumers: the advertiser can multihome and the platforms compete solely for the exclusive affiliation of consumers

ii) Competition for advertising: consumers can multihome (at no charge) and the platforms compete for the exclusive affiliation of a unique advertiser

iii) Two-sided competition: the platforms compete for the exclusive affiliation of both consumers and the independent advertiser.

Case (i) is most relevant for traditional advertising-supported media platforms such as television or newspapers, where consumers typically watch one channel or subscribe to one newspaper, whereas large advertisers typically place ads in multiple outlets. This is the "classic" case of competition among media platforms studied by Anderson and Coate (2005) and also used by Casadesus-Masanell and Zhu (2010). Case (i) also remains relevant for some Internet platforms

(e.g. e-commerce, search engines), where consumers tend to singlehome due to switching costs (habit formation, limited attention). By contrast, consumers may perceive low switching costs for other Internet platforms (e.g. online news), so that they routinely visit multiple sites. In such contexts, advertisers may prefer to singlehome due to budget constraints and to the fact they may be able to reach the same consumers on either platform. Case (iii) may seem like a more rare occurrence in reality, but it provides an interesting comparison point to cases (i) and (ii). Furthermore, the underlying mechanisms are quite different. 
Note that we omit the fourth logical scenario, in which both sides multihome: in that case there would be no competition for participation on either side, which is our focus. ${ }^{5}$

In all three competition scenarios, the timing is the same as in the monopoly case. Platforms $\mathrm{A}$ and $\mathrm{B}$ commit simultaneously to $s_{A}$ and $s_{B}$ respectively in stage 1 (publicly and credibly), then simultaneously set fees $r_{A}$ and $r_{B}$ to be paid by the advertiser in stage 2 . The other stages are similar, with agents (advertiser and consumers) choosing to affiliate exclusively or not, depending on the competition scenario. When a consumer is affiliated with both platforms, her stage 5 utility from engaging in product search on one platform is independent of what she does on the other platform.

We have separated the choices of $s_{i}$ and $r_{i}$ between the first two stages of the game in order to better reflect reality: fees charged to sellers are typically set after committing to platform design. Our equilibrium characterization below would be the same if we worked with the entire space of $\left(s_{i}, r_{i}\right)$ deviations. The difference is that the set of equilibrium conditions to satisfy would be significantly more complicated; this is another reason for adopting our simpler set-up.

\subsection{Competition for consumers}

In this scenario, the advertiser multihomes whereas consumers singlehome. In stage 2, each platform sets $r_{i}=\pi$ and the advertiser affiliates with both platforms. ${ }^{6}$

If $t$ is not too large so that the two platforms actually compete against each other, then platform $i$ 's profits from the perspective of stage 1 are:

$$
\Pi_{i}=X\left(s_{i}, \pi\right)\left(\frac{1}{2}+\frac{V\left(s_{i}\right)-V\left(s_{j}\right)}{2 t}\right)
$$

In this case, the equilibrium level of search diversion solves:

$$
s_{X V 2}(\pi, t)=\arg \max _{s}\left\{X(s, \pi)\left(\frac{1}{2}+\frac{V(s)-V\left(s_{X V 2}(\pi, t)\right)}{2 t}\right)\right\}
$$

\footnotetext{
${ }^{5}$ Despite the absence of competition when both sides multihome, the multiplicity of offers reduces the profit of each platform because there may be competition in terms of service usage (as opposed to participation). See Caillaud and Jullien (2003), Athey, Calvano and Gans (2012), Ambrus, Calvano and Reisinger (2012) or Taylor (2012).

${ }^{6}$ This scenario is equivalent to assuming that each platform is vertically integrated into products 1 and 2.
} 
In contrast, if $t$ is large, then each platform acts as a local monopolist and chooses the monopoly level of search diversion. Relegating the remaining details to the appendix, we obtain:

Lemma 1 There exists $\bar{t}_{1}>V\left(s_{X V}(\pi)\right)$ such that the symmetric equilibrium level of search diversion when platforms compete for consumers only is:

$$
s_{c}^{*}(\pi, t)=\left\{\begin{array}{ccc}
s_{X V 2}(\pi, t) & \text { if } & 0 \leq t \leq \bar{t}_{1} \\
V^{-1}\left(\frac{t}{2}\right) & \text { if } & \bar{t}_{1} \leq t \leq 2 V\left(s_{X V}(\pi)\right) \\
s_{X V}(\pi) & \text { if } & t \geq 2 V\left(s_{X V}(\pi)\right)
\end{array}\right.
$$

It is increasing in $t$ for $t \in\left[0, \bar{t}_{1}\right]$, decreasing in $t$ for $t \in\left[\bar{t}_{1}, 2 V\left(s_{X V}(\pi)\right)\right]$, and everywhere (weakly) increasing in $\pi$.

On the interval $t \in\left[0, \bar{t}_{1}\right]$, i.e. when platforms compete, $t$ has the opposite effect on $s_{c}^{*}$ relative to $s^{M}$. To explain this, recall that the level of search diversion results from a trade-off between revenue per user $(1+s r)$ and total participation by consumers. The latter becomes less elastic when competition for consumers is less intense (larger $t$ ), which shifts the trade-off towards extracting more revenues per user, i.e. towards more diversion. On the other hand, if $t$ is above the $\bar{t}_{1}$ threshold, then platforms no longer compete against each other, therefore $s_{c}^{*}$ is decreasing in $t$, just like $s^{M}$. The comparative statics in $\pi$ is the same as for the monopoly platform and the same interpretation applies.

We can now compare $s_{c}^{*}$ with $s^{M}$ :

Proposition 2 Relative to the level of search diversion chosen by a monopoly platform, the equilibrium level of search diversion when platforms compete for consumers only is strictly lower for low $t$, strictly higher for intermediate $t$, and equal for large $t$. Specifically:

$$
\text { - } s_{c}^{*}(\pi, t)<s^{M}(\pi, t) \text { for } 0 \leq t<V\left(s_{X V}(\pi)\right)
$$


- $s_{c}^{*}(\pi, t)>s^{M}(\pi, t)$ for $V\left(s_{X V}(\pi)\right)<t<2 V\left(s_{X V}(\pi)\right)$

- $s_{c}^{*}(\pi, t)=s^{M}(\pi, t)$ for $t \geq 2 V\left(s_{X V}(\pi)\right)$

To illustrate, Figure 1 represents $s_{c}^{*}$ and $s^{M}$ as functions of $t$.

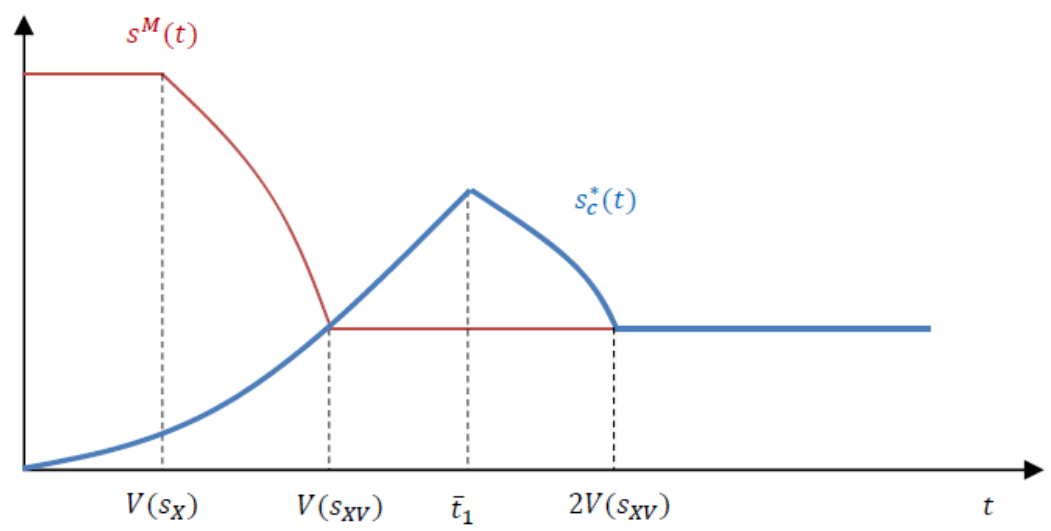

Figure 1

Restricting attention to the region of interest $t \in\left[0, \bar{t}_{1}\right]$ (on which platforms actually compete), our model predicts that the equilibrium level of search diversion with competing platforms is lower than the one chosen by a monopolist when competition is intense (low $t$ ) and higher when competition is not too intense (high $t$ ). When $t$ is small, the total consumer participation for the monopolist does not depend on search diversion - it is fixed at 1. Therefore, the monopolist only accounts for the effect of search diversion on revenues per participating consumer, $X(s, \pi)$. In contrast, when $t$ is small, competing platforms must take into account the effect of their respective levels of search diversion not just on revenues per participating consumer, but also on overall consumer participation. Since total consumer demand for a given platform is decreasing in the level of search diversion, it is natural that competing platforms end up choosing a lower equilibrium level of search diversion. Consider now that case when $t$ is large enough so that the monopolist no longer finds it optimal to attract all consumers. In this case, the marginal effect of search diversion perceived by the monopolist incorporates both the effect on revenues per participating consumer $\left(X_{s}(s, \pi)\right)$ and the effect on total consumer participation $\left(V^{\prime}(s) / t\right)$. If $t$ is not too large so that competing platforms are still constrained by competition for consumers, then they also take into account both effects. The only difference 
is that each competing platform perceives a marginal (negative) effect of search diversion on total consumer demand equal to $V^{\prime}(s) / 2 t$, which is half of the effect perceived by the monopolist. This simply reflects the fact that competitive pressure reduces platforms' ability to gain additional consumer participation. As a result, in this case the monopolist ends up choosing a lower level of search diversion than the competing platforms.

One can also interpret this result (competing platforms diverting search more than a monopolist) by relying on the elasticity of consumer participation with respect to search diversion. This elasticity is $-s V^{\prime}(s) / V(s)$ in the case of a monopoly that does not cover the entire consumer market (i.e. $t>V(s)$ ), whereas it is equal to $-s V^{\prime}(s) / t$ for a duopoly with equal market shares. Thus, if $t>V(s)$ then the former elasticity is larger, which leads to less search diversion under monopoly. On the other hand, the opposite holds if the monopolist covers the entire consumer market $\left(t<V\left(s_{X V}(\pi)\right)\right)$ : the monopolist's choice of search diversion ignores the impact on consumer affiliation decisions, which competing platforms can never ignore.

\subsection{Competition for unsolicited content}

Consider now the opposite scenario relative to the previous subsection: consumers can costlessly multihome and the platforms compete for the exclusive affiliation of an advertiser. Specifically, we assume that the platforms offer non-substitutable versions of product 1 (content), so that a consumer who affiliates with both intermediaries derives utility $2 u$ from consuming the two versions of product 1 (gross of search and transportation costs). We assume the advertiser affiliates exclusively with one platform. ${ }^{7}$

If the advertiser affiliates with platform $\mathrm{A}$, then platform A profits are $X\left(s_{A}, r_{A}\right) \min \left(V\left(s_{A}\right) / t, 1\right)$, whereas platform B profits are $F(u) \min (V(0) / t, 1)$. The advertiser's payoff is

$$
\left(\pi-r_{A}\right) s_{A} F\left(\frac{u}{1+s_{A}}\right) \min \left(\frac{V\left(s_{A}\right)}{t}, 1\right)=\left(X\left(s_{A}, \pi\right)-X\left(s_{A}, r_{A}\right)\right) \min \left(\frac{V\left(s_{A}\right)}{t}, 1\right) .
$$

Relegating the remaining details to the appendix, we obtain:

\footnotetext{
${ }^{7}$ Exclusive affiliation by the advertiser could be obtained endogenously by assuming that, for each consumer, only the first product exposure matters and that there is a sufficiently large probability that the same consumers are exposed to advertising on both platforms (see Athey Calvano and Gans 2012).
} 
Proposition 3 When consumers multihome and platforms compete for the exclusive affiliation of an advertiser, the equilibrium level of search diversion is the same as that chosen by a monopoly platform: $s_{a}^{*}(\pi, t)=s^{M}(\pi, t)$.

Thus, competition for product 2 (advertising) does not affect search diversion relative to a monopolist. This result is driven by Bertrand competition for the advertiser. Each platform $i$ sets its search diversion level $s_{i}$ to maximize its joint profits with the advertiser when the latter affiliates with $i$ exclusively, i.e. $X\left(s_{i}, \pi\right) \min \left(V\left(s_{i}\right) / t, 1\right)$. Then both platforms compete in fees $r_{i}$ so that the advertiser ends up capturing all of the joint profits in excess of each platform's outside option, $F(u) \min (V(0) / t, 1)$, which does not depend on search diversion levels. Consequently, although competition shifts the split of the joint vertical profit in favor of the advertiser, it is still optimal for platforms to choose the design that maximizes this joint profit. The difference is that a monopoly platform maximizes the value that can be extracted from the advertiser, whereas competing platforms seek to maximize the chance to attract the advertiser.

\subsection{Competition for both consumers and advertising}

Let us now turn to the case in which the two platforms compete for exclusive affiliation on both sides of the market. The full analysis of this competition scenario turns out to be significantly more complex than for the previous two cases and is therefore provided in the Online Appendix. Here, we highlight the main feature of the resulting equilibrium.

The key difference with the two previous competition scenarios is that here it is no longer clear whether both platforms wish to compete for the advertiser. To see why, suppose platform A "wins" the exclusive affiliation of the advertiser in Stage 2. Then the "losing" platform B obtains higher consumer demand, which may compensate for its lower revenues per consumer (no advertising). Thus, given the levels of search diversion set in stage 1, it is possible that B obtains a larger profit without the advertiser than the maximum profit it could expect to achieve if it were to attract the advertiser. When this is the case, platform B prefers not to make 
an offer to the advertiser in stage 2 and platform $\mathrm{A}$ is a de facto monopoly on the advertiser side of the market. As a result, the level of search diversion chosen by platform A simply maximizes its joint profits with the advertiser, conditional on platform B not having any advertising at all.

The alternative scenario is when platform B does indeed wish to compete for the advertiser in Stage 2 of the game. Then the equilibrium level of search diversion chosen by platform A maximizes total industry profits, i.e. including the advertiser and both platforms. The reason that platform B's profit is taken into account is as follows: A must offer the advertiser a payoff just above the largest payoff that can be offered by $\mathrm{B}$, which is the difference between its joint profit with the advertiser and what B gets when the advertiser affiliates with A. Raising the latter (i.e. B's outside option) reduces B's benefits from winning the contest for the advertiser and thereby decreases the value A needs to forego in order to attract the advertiser. In particular, if the advertiser affiliates with $\mathrm{A}$, increasing search diversion by platform $\mathrm{A}$ raises platform B's profit because it leads more consumers go to B instead of A. In other words, when it expects platform B to compete for the advertiser, the winning platform A maximizes total industry profit because it internalizes the fact that yielding more consumer demand to platform B (through more search diversion) reduces the cost of attracting the advertiser, by reducing platform B's willingness to compete.

In both scenarios, the comparative statics of the equilibrium level of search diversion in $(t, \pi)$ are the same as in the case of competition for consumers and interpreted in the same way.

Relegating the full analysis to the Online Appendix, we directly provide the main result:

Proposition 4 Relative to the level of search diversion chosen by a monopoly platform $s^{M}(\pi, t)$, the maximum level of search diversion that can be sustained in equilibrium when platforms compete for both consumers and the advertiser, $s^{*}(\pi, t)$, is strictly lower for low $t$ and strictly higher for large $t$. Specifically, there exist $\bar{t}_{2} \in[0, V(0)]$ and $\bar{t}_{3}>V(0)$ such that:

$$
\begin{aligned}
& \text { - } s^{*}(\pi, t) \leq s^{M}(\pi, t) \text { for } 0 \leq t \leq \bar{t}_{2} \\
& \text { - } s^{*}(\pi, t)>s^{M}(\pi, t) \text { for } \bar{t}_{2}<t \leq \bar{t}_{3}
\end{aligned}
$$


This result confirms the one obtained under competition for consumers only (despite a significantly more complex analysis): once again, the equilibrium level of search diversion with competing platforms is lower than the one chosen by a monopolist when competition is intense (low $t$ ) and higher when competition is not too intense (high $t$ ). The explanation is the same.

\section{Access fees}

In this section we introduce the possibility that platforms can charge access fees to consumers, denoted by $P$ and paid before search costs $c$ are observed. A priori, $P$ can be positive or negative. A negative access fee can be interpreted as a monetary subsidy (e.g. cash or redeemable points) or first-party content (beyond product 1) that consumers value at more than the price being charged.

The timing we use throughout this section (monopoly as well as competing platforms) is:

1. Platforms choose $s_{A}$ and $s_{B}$ simultaneously

2. Platforms choose $r_{A}$ and $r_{B}$ simultaneously

3. The advertiser decides which platform(s) to affiliate with

4. Platforms choose consumer access fees $P_{A}$ and $P_{B}$ simultaneously

5. Consumers decide which platform(s) to affiliate with

6. Affiliated consumers learn $c$ and engage in product search.

Our timing ensures that decisions regarding consumer access fees do not interfere with decisions affecting the quality of the services offered to consumers (search diversion). The value expected by consumers from each platform results from the combination of search diversion and the advertiser's affiliation decisions, and it is known at the time price competition for consumers occurs. $^{8}$ As in the previous sections, we have separated the choices of $s_{i}$ and $r_{i}$ between the first two stages of the game.

\footnotetext{
${ }^{8}$ This allows us to avoid coordination issues in affiliation decisions (see Caillaud and Jullien 2003), which are not the focus of this paper.
} 


\subsection{Monopoly}

The monopoly platform's profits are now:

$$
\max _{P, s}\left\{(P+X(s, \pi)) \min \left(\frac{V(s)-P}{t}, 1\right)\right\} .
$$

It is straightforward to obtain (details are in the appendix):

Proposition 5 The optimal level of search diversion for a monopoly platform that can charge access fees is:

$$
\widehat{s}^{M}(\pi)=s_{X+V}(\pi) \equiv \arg \max _{s}\{X(s, \pi)+V(s)\}
$$

Allowing the monopoly platform to charge access fees results in less search diversion $\left(\widehat{s}^{M} \leq s^{M}\right)$ if and only if the profit-maximizing access fee is non-negative $\left(\widehat{P}^{M} \geq 0\right)$

The first part of the proposition says that when the platform can monetize consumer participation, it chooses search diversion to maximize the joint surplus (platform + consumers) from participation. Also, note that just like $s^{M}(\pi)$, the level of search diversion with access fees $\widehat{s}^{M}(\pi)$ is weakly increasing in $\pi$.

The second part of the proposition says that the ability to monetize consumer participation reduces search diversion incentives. This result is intuitive: if the platform wishes to charge consumers a positive access fee, it must increase their willingness-to-pay, which means it needs to reduce search diversion. Conversely, a platform wishes to subsidize consumers when this sacrifice allows it to mitigate the effect of increasing search diversion on consumers' participation.

This result is consistent with some of the examples discussed in the introduction. Compare the websites of Forbes and The New York Times. Both rely on advertising, but The New York Times charges users a subscription fee, whereas access to Forbes is entirely free for users. Advertising on the New York Times web page is moderate; in contrast, advertising is highly intrusive on Forbes.com. A similar comparison applies to YouTube and Hulu. YouTube derives no revenues from first-party content or subscription fees and its advertisements are quite 
intrusive (sometimes 15 seconds with no opt-out before being able to watch a 2-minute video). Hulu relies on membership fees (Hulu Plus) and video-on-demand revenues - as a result, its advertisements are quite limited.

\subsection{Competition}

Consider the first competition scenario, in which the advertiser multihomes and consumers singlehome. In stage 2 the platforms set $r_{A}=r_{B}=\pi$, thus fully extracting the advertiser's surplus. As a result, stage 4 profits for platform $i$ are:

$$
\Pi_{i}=\left(P_{i}+X\left(s_{i}, \pi\right)\right)\left(\frac{1}{2}+\frac{V\left(s_{i}\right)-P_{i}-V\left(s_{j}\right)+P_{j}}{2 t}\right)
$$

Given $\left(s_{i}, s_{j}\right)$ chosen in stage 1 , the stage 2 pricing equilibrium is easily verified to be $P_{i}=$ $t+\left(V\left(s_{i}\right)-V\left(s_{j}\right)-X\left(s_{j}, \pi\right)-2 X\left(s_{i}, \pi\right)\right) / 3$, leading to stage 1 platform profits:

$$
\Pi_{i}\left(s_{i}, s_{j}\right)=\frac{t}{2}\left(1+\frac{V\left(s_{i}\right)+X\left(s_{i}, \pi\right)-V\left(s_{j}\right)-X\left(s_{j}, \pi\right)}{3 t}\right)^{2}
$$

Going backwards to stage 1, the symmetric equilibrium level of search diversion is:

$$
\widehat{s}_{c}^{*}(\pi)=\arg \max _{s}\{X(s, \pi)+V(s)\}=\widehat{s}^{M}(\pi) .
$$

In other words, we obtain the same level of search diversion as the one chosen by a monopoly platform. The following proposition (proven in the appendix) confirms that this is also true under the other two competition scenarios (their analysis is more complicated):

Proposition 6 When platforms can charge access fees, the equilibrium levels of search diversion under all three competition scenarios are the same as one another and equal to the level chosen by a platform monopolist:

$$
\widehat{s}_{c}^{*}(\pi)=\widehat{s}_{a}^{*}(\pi)=\widehat{s}^{*}(\pi)=s_{X+V}(\pi)=\widehat{s}^{M}(\pi)
$$


Furthermore, in the two competition scenarios in which one side multihomes, the equilibrium level of search diversion with access fees is lower relative to the case with no access fees if and only if the equilibrium access fee is positive.

Thus, when access fees are feasible, the equilibrium level of search diversion is identical to the one chosen by a monopoly platform. In this case, platforms maximize the joint surplus of the relationship with consumers and use the access fee to share this surplus with consumers. Competition only affects the level of the access fee.

In all three competition cases, the central part of the proof is showing that in the equilibrium of the game starting at stage 2 the advertiser affiliates with the platform $i$ that creates the highest joint surplus $X\left(s_{i}, \pi\right)+V\left(s_{i}\right)$. This was straightforward for the scenario with competition for consumers only, but turns out to be more complicated for the other two scenarios (cf. appendix).

The fundamental reason we obtain the equilibrium level of search diversion that maximizes $X(s, \pi)+V(s)$ for all monopoly and competition cases is that the access fee allows platforms to transfer surplus so all that matters beyond stage 1 of the game is the total surplus per consumer. The result for the scenario when the advertiser multihomes echoes similar results in Choi (2006) and Crampes, Haritchabalet and Jullien (2009). In all of these models, platforms maximize the joint platform-consumer surplus; this corresponds to total surplus per consumer in our model, because each platform extracts the entire profit from the vertical structure (platform plus advertiser).

The two scenarios with advertiser singlehoming are more complex because competition for the advertiser reduces the surplus that platforms can share with consumers (due to low advertising fees). Since consumer prices are set after the fees charged to the advertiser, opportunistic platform behaviour leads to consumer prices that are too high from the perspective of the vertical structure (platform and advertiser). For these two scenarios, we show that, despite this double marginalization, the total profit that can be promised by each platform to the advertiser remains increasing in the total surplus per consumer. Thus, in equilibrium, competition for the advertiser still leads the platform winning the advertiser to maximize the total surplus per consumer. Indeed, the platform generating the highest total surplus is able to offer better 
terms to the advertiser along with higher fees. Higher advertising fees act as a commitment device inducing the platform to reduce the price charged to consumers, which is beneficial for the vertical structure. This logic applies both when consumers multihome and when they singlehome.

For the second part of the proposition, the result and interpretation is the same as in the monopoly case above. If platforms charge positive access fees to consumers, they must offer them more value, i.e. less diversion. Conversely, if platforms subsidize the participation of consumers, they need to make up for the loss by increasing advertising revenues, which they can achieve by increasing diversion.

\section{Conclusion}

Our study of search diversion by competing platforms has yielded several important and novel insights (relative to Hagiu and Jullien 2011). First and most importantly, the effect of competition between platforms on the equilibrium level of search diversion is determined by the nature of competition. When horizontal differentiation between competing platforms in the eyes of consumers is reduced, the equilibrium level of search diversion decreases (i.e. search quality increases), as expected. On the other hand, we have shown that entry of a competitor may lead to more or at least as much search diversion as under monopoly. Specifically, when consumers singlehome, entry of a competitor leads to more (less) search diversion relative to monopoly when the degree of horizontal differentiation is intermediate (low). When the degree of horizontal differentiation is large, "competing" platforms behave as local monopolies and therefore divert search to the exact same extent as a monopolist would. An important result is that effective competition for exclusive affiliation on both sides of the market sometimes leads to a level of search diversion that maximizes total industry profit.

Second, allowing platforms to charge unrestricted access fees to consumers leads to the striking result that competing platforms choose the exact same level of search diversion as a monopoly platform, irrespective of the nature of competition and of the degree of horizontal 
differentiation. Furthermore, under monopoly and competition with at least one multihoming side, platforms that charge positive access fees to consumers have weaker incentives to divert search relative to platforms that cannot (or choose not to) charge such fees. On the other hand, platforms that subsidize consumer participation have stronger incentives to divert search.

\section{References}

[1] Anderson S. and Coate S. (2005), "Market Provision of Broadcasting: Welfare Analysis", Review of Economic Studies, 72(4), 947-972.

[2] Ambrus A., Calvano E. and Reisinger M. (2012) "A Two-Sided Theory of Advertising With Overlapping Viewership" working paper.

[3] Armstrong, M. (2006) "Competition in Two-Sided Markets," Rand Journal of Economics 37 (3), 669-691.

[4] Athey S., Calvano E. and Gans J. S. (2013) "The Impact of the Internet on Advertising Markets for News Media," NBER Working Paper No. 19419.

[5] Athey S., Gans J. S. (2010) "The Impact of Targeting Technology on Advertising Markets and Media Competition“, American Economic Review 100(2), 608-613.

[6] Boudreau, K.J. (2010) "Open Platform Strategies and Innovation: Granting Access vs. Devolving Control," Management Science 56(10), 1849-1872.

[7] Burguet, R., R. Caminal and M. Ellman (2013) "In Google we trust?," mimeo, Institut de Analisis Economica CSIC and Barcelona GSE.

[8] Caillaud, B., and B. Jullien (2003) "Chicken and Egg: Competition Among Intermediation Service Providers," Rand Journal of Economics 34(2), 309-328.

[9] Casadesus-Masanell, R. and Zhu F. (2010) "Strategies to Fight Ad-Sponsored Rivals," Management Science 56(9), 1484-1499. 
[10] Choi, J. P. (2006) "Broadcast competition and advertising with free entry: Subscription vs. free-to-air," Information Economics and Policy, 18(2), 181-196.

[11] Crampes, C., C. Haritchabalet and B. Jullien (2009) "Advertising, Competition and Entry in Media Industries," Journal of Industrial Economics, 57(1), 7-31.

[12] Eliaz, K. and Spiegler, R. (2011) "A Simple Model of Search Engine Pricing", The Economic Journal, 121(556): F329-F339.

[13] Ellman, M. and F. Germano (2009) "What do the papers sell? a model of advertising and media bias" The Economic Journal, 119(537): 680-704.

[14] Evans, D. and R. Schmalensee (2007) "The Industrial Organization of Markets with TwoSided Platforms," Competition Policy International, 3(1).

[15] Gabszewicz, J. J., D. Laussel and N. Sonnac (2006) "Competition in the Media and Advertising Markets," Manchester School, 74(1), 1-22.

[16] Ghose, A. and S. Yang (2009) "An empirical analysis of search engine advertising: Sponsored search in electronic markets." Management Science, 1-22.

[17] Hagiu, A. and B. Jullien (2011) "Why Do Intermediaries Divert Search?" Rand Journal of Economics 42(2), 337-362.

[18] Hagiu, A. and D. Spulber (2013) "First-Party Content and Coordination in Two-Sided Markets," Management Science, 59(4), 933-949.

[19] Hossain, T., D. Minor and J. Morgan (2011) "Competing Matchmakers: An Experimental Analysis," Management Science, 57, 1913-1925.

[20] Kaplan, S. and M. Sawhney (2000) "E-Hubs: The New B2B Marketplaces," Harvard Business Review, May-June 2000, R00306, 97-103.

[21] Parker, G. and M. W. Van Alstyne (2005) "Two-Sided Network Effects: A Theory of Information Product Design," Management Science, 51: 1494-1504. 
[22] Parker, G. and M. W. Van Alstyne (2008) "Innovation, Openness and Platform Control," working paper, Tulane University, Boston University and MIT.

[23] Peitz, M. and T. M. Valletti (2008) "Content and Advertising in the Media: Pay-TV Versus Free-to-Air," International Journal Industrial Organization, 26(4), 949-965.

[24] Petroski, H. (2003) Small Things Considered: Why There Is No Perfect Design, New York: Knopf.

[25] Rochet, J.-C., and J. Tirole (2006) "Two-Sided Markets: Where We Stand," Rand Journal of Economics, Vol. 37 (3), 645-66.

[26] Shih, W., S. Kaufman and D. Spinola (2007) "Netflix," Harvard Business School case study 9-607-138.

[27] Spence, M. (1975) "Monopoly, Quality and Regulation," Bell Journal of Economics, 6, 417-429.

[28] Taylor, G. (2013) "Search quality and revenue cannibalisation by competing search engines," Journal of Economics 83 Management Strategy, 22(3): 445-467,.

[29] Veiga, A. and G. Weyl (2012) "Multidimensional Product Design," working paper, Toulouse School of Economics and University of Chicago.

[30] Weyl, E. G. (2010) "A Price Theory of Multi-sided Platforms," American Economic Review, 100(4): 1642-72.

[31] White, A. (2013) "Search engines: Left side quality versus right side profits," International Journal of Industrial Organization, 31: 690-701.

\section{Appendix}

In order to reduce clutter, throughout the appendix we will drop the $(\pi, t)$ arguments of the various levels of $s$, unless they are needed for clarity. 


\subsection{Proof of Proposition 1}

If $t \in\left[V\left(s_{X}\right), V\left(s_{X V}\right)\right]$ then $s^{M}(\pi, t)=V^{-1}(t)$, decreasing in $t$ and constant in $\pi$.

If $t \leq V\left(s_{X}\right)$ then $s^{M}(\pi, t)=\arg \max _{s}\{X(s, \pi)\}$, so the F.O.C. determining $s^{M}$ can be written:

$$
F\left(\frac{u}{1+s}\right)-\left(\frac{1}{\pi}+s\right) \frac{u}{(1+s)^{2}} F^{\prime}\left(\frac{u}{1+s}\right)=0
$$

The left-hand side is increasing in $\pi$, which implies (assuming second-order conditions are satisfied) that $s^{M}(\pi, t)$ is increasing in $\pi$. It is obviously constant in $t$.

If $t \geq V\left(s_{X V}\right)$ then $s^{M}(\pi, t)=\arg \max _{s}\{X(s, \pi) V(s)\}$, so the F.O.C. determining $s^{M}$ is:

$$
\left(\frac{1}{\pi}+s\right) \cdot\left[\frac{-u}{(1+s)^{2}} F^{\prime}\left(\frac{u}{1+s}\right) V(s)+F\left(\frac{u}{1+s}\right) V^{\prime}(s)\right]+F\left(\frac{u}{1+s}\right) V(s)=0
$$

Since $V^{\prime}(s)<0$, the left-hand side is increasing in $\pi$, which implies (assuming second-order conditions are satisfied) that $s^{M}(\pi, t)$ is increasing in $\pi$ and constant in $t$.

\subsection{Proof of Lemma 1}

Given $s_{j}$, platform $i$ 's profits are:

$$
\Pi_{i}\left(s_{i}\right)=\left\{\begin{array}{ccc}
X\left(s_{i}, \pi\right)\left[\frac{1}{2}+\frac{V\left(s_{i}\right)-V\left(s_{j}\right)}{2 t}\right] & \text { if } & V\left(s_{i}\right)+V\left(s_{j}\right) \geq t \\
X\left(s_{i}, \pi\right) \frac{V\left(s_{i}\right)}{t} & \text { if } & V\left(s_{i}\right)+V\left(s_{j}\right) \leq t
\end{array}\right.
$$

There are therefore 3 possible equilibria:

1) $s_{c}^{*}=s_{X V 2}$, where $s_{X V 2}$ solves equation (6), so that $s_{X V 2}$ is determined by the following F.O.C.:

$$
X(s, \pi) V^{\prime}(s)+t X_{s}(s, \pi)=0
$$

From this, it is easily seen that $s_{X V 2}$ is increasing in $t$. It is also increasing in $\pi$ by a very similar argument to that employed in the proof of proposition 1. This is an equilibrium if and only if $V\left(s_{X V 2}\right) \geq t / 2$ (the consumer in the middle of the Hotelling segment obtains non-negative utility), i.e. only if $t \leq \bar{t}_{1}$, where $\bar{t}_{1}$ is uniquely defined by:

$$
V\left(s_{X V 2}\left(\pi, \bar{t}_{1}\right)\right)=\bar{t}_{1} / 2
$$


Furthermore, comparing (11) with (3) we have:

$$
s_{X V 2}\left(\pi, V\left(s_{X V}\right)\right)=s_{X V},
$$

so that $V\left(s_{X V 2}\left(\pi, V\left(s_{X V}\right)\right)\right)>V\left(s_{X V}\right) / 2$, which implies $\bar{t}_{1}>V\left(s_{X V}\right)$.

2) $s_{c}^{*}=s_{X V}$. This is an equilibrium if and only if $V\left(s_{X V}\right) \leq t / 2$, i.e. if and only if $t \geq 2 V\left(s_{X V}\right)$. Let us show that $2 V\left(s_{X V}\right)>\bar{t}_{1}$. The first-order conditions that determine $s_{X V 2}\left(\pi, \bar{t}_{1}\right)$ and $s_{X V}(\pi)$ are, respectively:

$$
\begin{aligned}
X(s, \pi) V^{\prime}(s)+2 V(s) X_{s}(s, \pi) & =0 \text { for } s_{X V 2}\left(\pi, \bar{t}_{1}\right) \\
X(s, \pi) V^{\prime}(s)+V(s) X_{s}(s, \pi) & =0 \text { for } s_{X V}(\pi)
\end{aligned}
$$

Comparing the two, it is clear that $s_{X V 2}\left(\pi, \bar{t}_{1}\right)>s_{X V}(\pi)$, which implies:

$$
\bar{t}_{1}=2 V\left(s_{X V 2}\left(\pi, \bar{t}_{1}\right)\right)<2 V\left(s_{X V}\right)
$$

3) $s_{c}^{*}=V^{-1}(t / 2)$. Suppose $s_{2}=V^{-1}(t / 2)$. If $s_{1} \geq V^{-1}(t / 2)$ then platform 1's profits are $X\left(s_{1}, \pi\right) V\left(s_{1}\right) / t$. Thus, for $s_{1}=V^{-1}(t / 2)$ to be a best response to $s_{2}=V^{-1}(t / 2)$, it must be that $s_{X V} \leq V^{-1}(t / 2)$, i.e. if $t \leq 2 V\left(s_{X V}\right)$.

If $s_{1} \leq V^{-1}(t / 2)$ then platform 1's profits are:

$$
X\left(s_{1}, \pi\right)\left(\frac{1}{2}+\frac{V\left(s_{1}\right)-t / 2}{2 t}\right)
$$

The maximizer $s^{*}$ of this profit expression is defined by the first-order condition:

$$
X\left(s^{*}, \pi\right) V^{\prime}\left(s^{*}\right)+\left(t / 2+V\left(s^{*}\right)\right) X_{s}\left(s^{*}, \pi\right)=0
$$

Thus, for $s_{1}=V^{-1}(t / 2)$ to be a best response to $s_{2}=V^{-1}(t / 2)$, it must be that $s^{*} \geq V^{-1}(t / 2)$, i.e. $V\left(s^{*}\right) \leq t / 2$, which implies:

$$
X\left(s^{*}, \pi\right) V^{\prime}\left(s^{*}\right)+2 V\left(s^{*}\right) X_{s}\left(s^{*}, \pi\right) \leq 0
$$


Comparing this with the first-order condition determining $s_{X V 2}\left(\pi, \bar{t}_{1}\right)$,

$$
X(s, \pi) V^{\prime}(s)+2 V(s) X_{s}(s, \pi)=0
$$

we have $s^{*} \leq s_{X V 2}\left(\pi, \bar{t}_{1}\right)$, which is equivalent to $V\left(s^{*}\right) \geq V\left(s_{X V 2}\left(\pi, \bar{t}_{1}\right)\right)=\bar{t}_{1} / 2$. Consequently, we must have $t \geq \bar{t}_{1}$.

Thus, $s_{c}^{*}=V^{-1}(t / 2)$ is an equilibrium if and only if $t \in\left[\bar{t}_{1}, 2 V\left(s_{X V}\right)\right]$. Note that $V^{-1}(t / 2)$ is decreasing in $t$.

\subsection{Proof of Proposition 2}

On the interval $t \in\left[0, \bar{t}_{1}\right]$, we know from proposition 1 and lemma 1 that $s^{M}$ is decreasing in $t$, whereas $s_{c}^{*}=s_{X V 2}$ is increasing in $t$. Furthermore, from (12), we have $s_{X V 2}=s_{X V}=s^{M}$ at $t=V\left(s_{X V}\right)$. We can conclude that $s_{c}^{*}<s^{M}$ for $t<V\left(s_{X V}\right)$ and $s_{c}^{*}>s^{M}$ for $V\left(s_{X V}\right)<t<\bar{t}_{1}$.

\subsection{Proof of Proposition 3}

Consider stage 3 . The advertiser's payoff from affiliating exclusively with platform $i$ is:

$$
\left(\pi-r_{i}\right) s_{i} F\left(\frac{u}{1+s_{i}}\right) \min \left(\frac{V\left(s_{i}\right)}{t}, 1\right)=\left(X\left(s_{i}, \pi\right)-X\left(s_{i}, r_{i}\right)\right) \min \left(\frac{V\left(s_{i}\right)}{t}, 1\right),
$$

while platform $i$ 's payoff is $X\left(s_{i}, r_{i}\right) \min \left(V\left(s_{i}\right) / t, 1\right)$. In stage 2 , platform $i$ is prepared to lower its fee $r_{i}$ until its payoff is equal to its outside option, $F(u) \min (V(0) / t, 1)$. Consequently, in the equilibrium of the game starting at stage 2, the advertiser affiliates with the platform that has the highest $X\left(s_{i}, r_{i}\right) \min \left(V\left(s_{i}\right) / t, 1\right)$. The fees in the stage 2 equilibrium are determined by:

$$
\left(X\left(s_{i}, \pi\right)-X\left(s_{i}, r_{i}\right)\right) \min \left(\frac{V\left(s_{i}\right)}{t}, 1\right)=X\left(s_{j}, \pi\right) \min \left(\frac{V\left(s_{j}\right)}{t}, 1\right)-F(u) \min \left(\frac{V(0)}{t}, 1\right)
$$

for the "winning" platform $i$ and:

$$
X\left(s_{j}, r_{j}\right) \min \left(\frac{V\left(s_{j}\right)}{t}, 1\right)=F(u)\left(\frac{V(0)}{t}, 1\right)
$$

for the "losing" platform $j$. 
Consider now stage 1. If $X\left(s_{i}, \pi\right) \min \left(V\left(s_{i}\right) / t, 1\right)>X\left(s_{j}, \pi\right) \min \left(V\left(s_{j}\right) / t, 1\right)$ then platform $i$ attracts the advertiser with probability 1 and obtains profits

$$
F(u) \min \left(\frac{V(0)}{t}, 1\right)+X\left(s_{i}, \pi\right) \min \left(\frac{V\left(s_{i}\right)}{t}, 1\right)-X\left(s_{j}, \pi\right) \min \left(\frac{V\left(s_{j}\right)}{t}, 1\right) .
$$

This is an equilibrium if and only if $s_{i}=\arg \max _{s}\{X(s, \pi) \min (V(s) / t, 1)\}$. If $X\left(s_{i}, \pi\right) \min \left(V\left(s_{i}\right) / t, 1\right)=$ $X\left(s_{j}, \pi\right) \min \left(V\left(s_{j}\right) / t, 1\right)$ then the advertiser is indifferent between affiliating with either platform and both platforms' profits are equal to $F(u) \min (V(0) / t, 1)$. This is an equilibrium if and only if $s_{i}=s_{j}=\arg \max _{s}\{X(s, \pi) \min (V(s) / t, 1)\}$. Thus, we have proven that the equilibrium level of search diversion in all cases is $\arg \max _{s}\{X(s, \pi) \min (V(s) / t, 1)\}=s^{M}(\pi, t)$.

\subsection{Proof of Proposition 5}

Denote by $\left(\widehat{P}^{M}, \widehat{s}^{M}\right)$ the solutions to the optimization program:

$$
\max _{P, s}\left\{(P+X(s, \pi)) \min \left(\frac{V(s)-P}{t}, 1\right)\right\}
$$

There are only two possibilities:

- if $V\left(\widehat{s}^{M}\right)-\widehat{P}^{M} \geq t$ then it must be that $\widehat{P}^{M}=V\left(\widehat{s}^{M}\right)-t$ and profits are equal to $V\left(\widehat{s}^{M}\right)+$ $X\left(\widehat{s}^{M}, \pi\right)-t$, which means we must have $\widehat{s}^{M}=s_{X+V}$

- if $V\left(\widehat{s}^{M}\right)-\widehat{P}^{M}<t$ then it must be that $\widehat{P}^{M}=\left(V\left(\widehat{s}^{M}\right)-X\left(\widehat{s}^{M}, \pi\right)\right) / 2$ and profits are equal to $\left(V\left(\widehat{s}^{M}\right)+X\left(\widehat{s}^{M}, \pi\right)\right)^{2} / 4 t$, so that we must have $\widehat{s}^{M}=s_{X+V}$

Thus, $\widehat{s}^{M}=s_{X+V}$ in all cases. The first-order condition determining $s_{X+V}$ can then be written:

$$
\frac{-u}{(1+s)^{2}} F^{\prime}\left(\frac{u}{1+s}\right)+F\left(\frac{u}{1+s}\right)+V^{\prime}(s) / \pi=0
$$

The left-hand side is increasing in $\pi$, which implies (assuming the second-order condition is satisfied) that $s_{X+V}$ is increasing in $\pi$.

The optimal access fee is:

$$
\widehat{P}^{M}=\left\{\begin{array}{cl}
V\left(s_{X+V}\right)-t & \text { if } t \leq\left(V\left(s_{X+V}\right)+X\left(s_{X+V}, \pi\right)\right) / 2 \\
\left(V\left(s_{X+V}\right)-X\left(s_{X+V}, \pi\right)\right) / 2 & \text { if } t \geq\left(V\left(s_{X+V}\right)+X\left(s_{X+V}, \pi\right)\right) / 2
\end{array}\right.
$$


Now compare $s_{X+V}$ and $s_{X V}$ by looking at the first-order conditions that determine them:

$$
\begin{aligned}
X_{s}\left(s_{X+V}, \pi\right)+V^{\prime}\left(s_{X+V}\right) & =0 \\
X_{s}\left(s_{X V}, \pi\right) V\left(s_{X V}\right)+X\left(s_{X V}, \pi\right) V^{\prime}\left(s_{X V}\right) & =0
\end{aligned}
$$

It is thus apparent that $\max \left\{s_{X+V}, s_{X V}\right\} \leq s_{X}$ and $s_{X+V} \leq s_{X V}$ if and only if $V\left(s_{X+V}\right) \geq$ $X\left(s_{X+V}, \pi\right)$. Consider then the two possible cases:

- If $V\left(s_{X+V}\right) \geq X\left(s_{X+V}, \pi\right)$ then $\widehat{P}^{M} \geq 0$ for all $t$ and $s_{X+V} \leq s_{X V}$. Recalling the expression of $s^{M}(t, \pi)$ from 4 , this implies that $\widehat{s}^{M}(\pi) \leq s^{M}(t, \pi)$ for all $t$

- If $V\left(s_{X+V}\right)<X\left(s_{X+V}, \pi\right)$ then $\widehat{P}^{M} \geq 0$ if and only if $t \leq V\left(s_{X+V}\right)$. But in this case we also have $s_{X}>s_{X+V}>s_{X V}$, i.e. $V\left(s_{X}\right)<V\left(s_{X+V}\right)<V\left(s_{X V}\right)$, which implies that $s^{M}\left(V\left(s_{X+V}\right), \pi\right)=s_{X+V}=\widehat{s}^{M}(\pi)$. Since $s^{M}(t, \pi)$ is decreasing in $t$, we therefore conclude that $\widehat{s}^{M}(\pi) \leq s^{M}(t, \pi)$ if and only if $t \leq V\left(s_{X+V}\right)$.

Thus, we have shown that in all cases, $\widehat{s}^{M} \leq s^{M}$ if and only if $\widehat{P}^{M} \geq 0$.

\subsection{Proof of Proposition 6}

\subsubsection{Consumers singlehome and the advertiser multihomes}

The determination of the equilibrium level of search diversion $\widehat{s}_{c}^{*}(\pi)$ is in the main text. For the second part of the proposition, the equilibrium access fee charged by the two platforms is $P_{c}^{C}=$ $t-X\left(\widehat{s}_{c}^{*}(\pi), \pi\right)$. The two first order conditions that determine $\widehat{s}_{c}^{*}(\pi)$ and $s_{c}^{*}(\pi)=s_{X V 2}$ (focusing on the case in which platforms actually compete) are, respectively:

$$
\begin{array}{r}
X^{\prime}\left(\widehat{s}_{c}^{*}, \pi\right)+V^{\prime}\left(\widehat{s}_{c}^{*}\right)=0 \\
X^{\prime}\left(s_{c}^{*}, \pi\right)+X\left(s_{c}^{*}, \pi\right) \frac{V^{\prime}\left(s_{c}^{*}\right)}{t}=0
\end{array}
$$

Comparing, it is easily seen that $\widehat{s}_{c}^{*} \leq s_{c}^{*}$ if and only if $t \geq X\left(\widehat{s}_{c}^{*}(\pi), \pi\right)$, i.e. if and only if $P_{c}^{C} \geq 0$.

\subsubsection{Consumers multihome and the advertiser singlehomes}

Suppose that in stage 3 the advertiser affiliates with platform $i \in\{A, B\}$. Then, in stage 4 , platform $i$ 's profits are $\left(P_{i}+X\left(s_{i}, r_{i}\right)\right) \min \left\{\left(V\left(s_{i}\right)-P_{i}\right) / t, 1\right\}$, which it optimizes over $P_{i}$ to obtain profits 
equal to $\Pi_{P}\left(V_{i}\left(s_{i}\right)+X\left(s_{i}, r_{i}\right)\right)$, where:

$$
\Pi_{P}(z) \equiv\left\{\begin{array}{cc}
\frac{z^{2}}{4 t} & \text { if } \quad z \leq 2 t \\
z-t & \text { if } \quad z \geq 2 t
\end{array}\right.
$$

Clearly, $\Pi_{P}($.$) is increasing. In turn, platform j$ 's stage 4 profits are $\Pi_{P}(V(0)+F(u)) \equiv \Pi_{0}$.

The advertiser's payoff from affiliation with platform $i$ is then:

$$
\Pi_{a d v}^{i}=\left(\pi-r_{i}\right) s_{i} F\left(\frac{u}{1+s_{i}}\right) \min \left(\frac{V\left(s_{i}\right)+X\left(s_{i}, r_{i}\right)}{2 t}, 1\right)
$$

In Stage 2, platforms choose $\left(r_{A}, r_{B}\right)$ taking $\left(s_{A}, s_{B}\right)$ as given, which is equivalent to choosing $\left(Z_{A}, Z_{B}\right)$, where:

$$
Z_{A} \equiv V\left(s_{A}\right)+X\left(s_{A}, r_{A}\right) \text { and } Z_{B} \equiv V\left(s_{B}\right)+X\left(s_{B}, r_{B}\right)
$$

Indeed, recall that $X\left(s_{i}, r_{i}\right)$ is increasing in $r_{i}$ so there is a one-to-one relationship between $r_{i}$ and $Z_{i}$ for each $i \in\{A, B\}$.

To simplify notation, we also denote:

$$
W_{i} \equiv V\left(s_{i}\right)+X\left(s_{i}, \pi\right) \text { and } V_{i} \equiv V\left(s_{i}\right) \text { for } i \in\{A, B\}
$$

which are fixed from the perspective of stage 2 .

The advertiser's payoff from affiliation with platform $i$ is then:

$$
\left(W_{i}-Z_{i}\right) \min \left(\frac{Z_{i}}{2 t}, 1\right) \equiv \Pi_{a d v}\left(Z_{i}, W_{i}\right)
$$

It is easily seen that $\Pi_{a d v}\left(Z_{i}, W_{i}\right)$ is single-peaked in $Z_{i}$ and increasing in $W_{i}$. Let also:

$$
\widehat{Z}(W) \equiv \arg \max _{Z}\left\{\Pi_{a d v}(Z, W)\right\}=\left\{\begin{array}{ccc}
\frac{W}{2} & \text { if } \quad \frac{W}{4 t} \leq 1 \\
2 t & \text { if } & \frac{W}{4 t} \geq 1
\end{array}\right.
$$

We first prove the following lemma:

Lemma 2 In the stage 2 equilibrium, if the advertiser affiliates with platform $i$ then $W_{i} \geq W_{j}$.

Proof. If the advertiser affiliates with platform $i$ in stage 3, then in the stage 2 equilibrium (choices 
of $Z_{i}$ and $Z_{j}$ ) we must have:

$$
\begin{aligned}
\Pi_{i} & =\max _{Z_{i}}\left\{\Pi_{P}\left(Z_{i}\right)\right\} \quad \text { such that } \Pi_{a d v}\left(Z_{i}, W_{i}\right) \geq \Pi_{a d v}^{j} \\
\Pi_{a d v}^{j} & =\max _{Z_{j}}\left\{\Pi_{a d v}\left(Z_{j}, W_{j}\right)\right\} \quad \text { s.t. } \Pi_{P}\left(W_{j}\right) \geq \Pi_{0}
\end{aligned}
$$

Denote by $\left(Z_{i}^{*}, Z_{j}^{*}\right)$ the resulting equilibrium choices.

Since $\Pi_{P}\left(Z_{i}\right)$ is increasing in $Z_{i}$, whereas $\Pi_{a d v}\left(Z_{i}, W_{i}\right)$ is single-peaked in $Z_{i}$ and zero for $Z_{i}=$ $W_{i}$, in equilibrium the constraint in the program (14) must be binding with the highest possible value of $Z_{i}$, so that

$$
\Pi_{a d v}\left(Z_{i}^{*}, W_{i}\right)=\Pi_{a d v}^{j}
$$

There are two possibilities. First, if the constraint in program (15) is not binding in equilibrium then:

$$
\Pi_{a d v}^{j}=\max _{Z_{j}}\left\{\Pi_{a d v}\left(Z_{j}, W_{j}\right)\right\}=\max _{Z_{j}}\left\{\left(W_{j}-Y_{j}\right) \min \left(\frac{Z_{j}}{2 t}, 1\right)\right\}
$$

Combined with (14), this implies:

$$
\begin{aligned}
\max _{Z_{i}}\left\{\left(W_{i}-Z_{i}\right) \min \left(\frac{Z_{i}}{2 t}, 1\right)\right\} & \geq\left(W_{i}-Z_{i}^{*}\right) \min \left(\frac{Z_{i}^{*}}{2 t}, 1\right) \\
& =\max _{Z_{j}}\left\{\left(W_{j}-Z_{j}\right) \min \left(\frac{Z_{j}}{2 t}, 1\right)\right\}
\end{aligned}
$$

It is easily verified that this implies $W_{i} \geq W_{j}$.

Second, suppose instead the constraint in (15) is binding in equilibrium:

$$
\Pi_{P}\left(Z_{j}^{*}\right)=\Pi_{0} \leq \Pi_{P}\left(Z_{i}^{*}\right)
$$

where the last inequality is required in equilibrium (otherwise platform $i$ would prefer to not attract the advertiser). Since $\Pi_{P}($.$) is increasing, this is equivalent to:$

$$
Z_{j}^{*}=V(0)+F(u) \leq Z_{i}^{*}
$$

Furthermore, if the constraint in (15) binds then $Z_{j}=\widehat{Z}\left(W_{j}\right)$ violates the constraint, i.e.

$$
\widehat{Z}\left(W_{j}\right)<V(0)+F(u)
$$


Once again, there are two possibilities:

- If $\widehat{Z}\left(W_{i}\right) \geq V(0)+F(u)$ then

$$
\widehat{Z}\left(W_{i}\right)>\widehat{Z}\left(W_{j}\right)
$$

From (13), this is only possible if $W_{i}>W_{j}$ (and $W_{j}<4 t$ ).

- If $\widehat{Z}\left(W_{i}\right)<V(0)+F(u)$ then (16) and (14) imply

$$
\begin{aligned}
& \Pi_{a d v}\left(Z_{i}^{*}, W_{i}\right) \leq \Pi_{a d v}\left(V(0)+F(u), W_{i}\right) \\
& \Pi_{a d v}\left(Z_{i}^{*}, W_{i}\right)=\Pi_{a d v}\left(Z_{j}^{*}, W_{j}\right)=\Pi_{a d v}\left(F(u)+V(0), W_{j}\right),
\end{aligned}
$$

which implies

$$
\Pi_{a d v}\left(V(0)+F(u), W_{i}\right) \geq \Pi_{a d v}\left(F(u)+V(0), W_{j}\right),
$$

i.e. $W_{i} \geq W_{j}$.

Suppose that in equilibrium platform A wins the advertiser. Then $W_{A} \geq W_{B}$ and platform A's profits can we rewritten:

$$
\begin{aligned}
\Pi_{A} & =\Pi_{w}\left(s_{A}, s_{B}\right) \equiv \max _{Z_{A}}\left\{\Pi_{P}\left(Z_{A}\right)\right\} \\
\text { s.t. }\left(W_{A}-Z_{A}\right) \min \left(\frac{Z_{A}}{2 t}, 1\right) & \geq \Pi_{a d v}\left(s_{B}\right)
\end{aligned}
$$

where:

$$
\Pi_{a d v}\left(s_{B}\right) \equiv \max _{Z_{B}}\left\{\frac{\left(W_{B}-Z_{B}\right) Z_{B}}{2 t}\right\} \quad \text { s.t. } \Pi_{P}\left(Z_{B}\right) \geq \Pi_{0}
$$

Suppose there exists $s_{A}^{\prime}$ such that $W_{A}^{\prime}=X\left(s_{A}^{\prime}, \pi\right)+V\left(s_{A}^{\prime}\right)>W_{A}=X\left(s_{A}, \pi\right)+V\left(s_{A}\right)$, which implies $W_{A}^{\prime}>W_{B}$. Thus, if platform A deviates to $s_{A}^{\prime}$ in stage 1 then it wins the advertiser in stage 2 with probability 1 . Furthermore, since $\Pi_{a d v}\left(s_{B}\right)$ remains unchanged, the optimization problem above immediately implies $\Pi_{w}\left(s_{A}^{\prime}, s_{B}\right)>\Pi_{w}\left(s_{A}, s_{B}\right)$. Therefore $s_{A}^{\prime}$ is a profitable deviation. Thus, it must be that in the stage 1 equilibrium $s_{A}=s_{X+V} \equiv \arg \max _{s}\{X(s, \pi)+V(s)\}$.

If $s_{B} \neq s_{X+V}$ then platform B makes profits $\Pi_{0}$ with probability 1 and $\Pi_{0}$ does not depend on $s_{B}$. If $s_{B}=s_{A}=s_{X+V}$ then we may assume that $A$ wins the advertiser with probability 1 . Thus, in 
all cases it is an equilibrium that platform $A$ chooses $s_{A}=s_{X+V}$ and wins the advertiser.

For the second part of the proposition corresponding to this scenario, simply note that $\widehat{s}_{a}^{*}=\widehat{s}^{M}$ (which we have just proven) and $s_{a}^{*}=s^{M}$ (from proposition 3). And we have already proven that $\widehat{s}^{M} \leq s^{M}$ if and only if $P^{M} \geq 0$ (proposition 5). We can therefore directly conclude that $\widehat{s}_{a}^{*} \leq s_{a}^{*}$ if and only if $P_{a}^{*} \geq 0\left(\right.$ since $\left.P_{a}^{*}=P^{M}\right)$.

\subsubsection{Both sides singlehome}

Suppose that in stage 3 the advertiser affiliates with platform $i \in\{A, B\}$. Then, in stage 4 , platform $i$ and platform $j$ 's profits are, respectively:

$$
\begin{aligned}
& \left(P_{i}+X\left(s_{i}, r_{i}\right)\right) \frac{1}{2 t}\left(t+V\left(s_{i}\right)-V(0)-P_{i}+P_{j}\right) \\
& \left(P_{j}+F(u)\right) \frac{1}{2 t}\left(t+V(0)-V\left(s_{i}\right)-P_{j}+P_{i}\right)
\end{aligned}
$$

Calculating the Nash equilibrium in prices, we obtain that stage 4 equilibrium profits are, respectively:

$$
\begin{aligned}
\Pi_{i} & =\frac{1}{2 t}\left(t+\frac{V\left(s_{i}\right)+X\left(s_{i}, r_{i}\right)-V(0)-F(u)}{3}\right)^{2} \\
\Pi_{j} & =\frac{1}{2 t}\left(t+\frac{V(0)+F(u)-V\left(s_{i}\right)-X\left(s_{i}, r_{i}\right)}{3}\right)^{2}
\end{aligned}
$$

The advertiser's payoff from affiliation with platform $i$ is then:

$$
\Pi_{a d v}^{i}=\left(X\left(s_{i}, \pi\right)-X\left(s_{i}, r_{i}\right)\right) \frac{1}{2 t}\left(t+\frac{V\left(s_{i}\right)+X\left(s_{i}, r_{i}\right)-V(0)-F(u)}{3}\right)
$$

In Stage 2, platforms choose $\left(r_{A}, r_{B}\right)$ taking $\left(s_{A}, s_{B}\right)$ as given, which is equivalent to choosing $\left(Z_{A}, Z_{B}\right)$, where:

$$
Z_{i} \equiv X\left(s_{i}, r_{i}\right)+V\left(s_{i}\right)
$$

Indeed, recall that $X\left(s_{i}, r_{i}\right)$ is increasing in $r_{i}$ so there is a one-to-one relationship between $r_{i}$ and $Z_{i}$ for each $i \in\{A, B\}$.

Denote also:

$$
\begin{aligned}
W_{i} & \equiv X\left(s_{i}, \pi\right)+V\left(s_{i}\right) \text { for } i \in\{1,2\} \\
W_{0} & \equiv V(0)+F(u)
\end{aligned}
$$


which are fixed from the perspective of stage 2 .

Suppose that platform $i$ wins the advertiser. Then platform profits in stage 4 can be written:

$$
\begin{aligned}
& \Pi_{i}=\Pi_{w}\left(Z_{i}\right) \equiv \frac{1}{2 t}\left(t+\frac{Z_{i}-W_{0}}{3}\right)^{2} \\
& \Pi_{j}=\Pi_{l}\left(Z_{i}\right) \equiv \frac{1}{2 t}\left(t+\frac{W_{0}-Z_{i}}{3}\right)^{2}
\end{aligned}
$$

Meanwhile, the advertiser's payoff from affiliation with platform $i$ is:

$$
\Pi_{a d v}\left(Z_{i}, W_{i}\right) \equiv\left(W_{i}-Z_{i}\right) \frac{1}{2 t}\left(t+\frac{Z_{i}-W_{0}}{3}\right)
$$

First, we prove the following lemma:

Lemma 3 In the stage 3 equilibrium, if the advertiser affiliates with platform $i$ then $W_{i} \geq W_{j}$.

Proof. Suppose platform $i$ wins the advertiser in the equilibrium of the stage 2 game and denote by $\left(Z_{i}^{*}, Z_{j}^{*}\right)$ the equilibrium choices in stage 2 . We must then have:

$$
\begin{aligned}
Z_{i}^{*} & =\arg \max _{Z_{i}}\left\{\Pi_{w}\left(Z_{i}\right)\right\} \text { s.t. } \Pi_{a d v}\left(Z_{i}, W_{i}\right) \geq \widehat{\Pi}_{a d v}\left(W_{j}, \Pi_{l}\left(Z_{i}^{*}\right)\right) \\
\widehat{\Pi}_{a d v}\left(W_{j}, \Pi_{l}\left(Z_{i}^{*}\right)\right) & \equiv \max _{Z_{j}}\left\{\Pi_{a d v}\left(Z_{j}, W_{j}\right)\right\} \text { s.t. } \Pi_{w}\left(Z_{j}\right) \geq \Pi_{l}\left(Z_{i}^{*}\right)
\end{aligned}
$$

Since $\Pi_{w}\left(Z_{i}\right)$ is increasing in $Z_{i}$, whereas $\Pi_{a d v}\left(Z_{i}, W_{i}\right)$ is concave in $Z_{i}$ and equals 0 at $Z_{i}=W_{i}$, in equilibrium the constraint in (21) must be binding and $\Pi_{a d v}\left(Z_{i}, W_{i}\right)$ must be decreasing in $Z_{i}$ at the point $Z_{i}=Z_{i}^{*}$ where it intersects $\widehat{\Pi}_{a d v}\left(W_{j}, \Pi_{l}\left(Z_{i}^{*}\right)\right)$. This is equivalent to:

$$
W_{i}-3 t+W_{0} \leq 2 Z_{i}^{*}
$$

Suppose the constraint in (22) is not binding. Then in equilibrium:

$$
\begin{aligned}
Z_{j}^{*} & =\frac{W_{j}-3 t+W_{0}}{2} \\
\widehat{\Pi}_{a d v}\left(W_{j}, \Pi_{l}\left(Z_{i}^{*}\right)\right) & =\frac{1}{24 t}\left(3 t+W_{j}-W_{0}\right)^{2}
\end{aligned}
$$

so that:

$$
\frac{1}{24 t}\left(3 t+W_{i}-W_{0}\right)^{2} \geq \frac{\left(W_{i}-Z_{i}^{*}\right)}{2 t}\left(t+\frac{Z_{i}^{*}-W_{0}}{3}\right)=\frac{1}{24 t}\left(3 t+W_{j}-W_{0}\right)^{2}
$$


which directly implies $W_{i} \geq W_{j}$.

Suppose now the constraint in (22) is binding, which means:

$$
Z_{j}^{*}-W_{0}=W_{0}-Z_{i}^{*}
$$

Furthermore, this requires that the peak of $\Pi_{a d v}\left(Z_{j}, W_{j}\right)$ in $Z_{j}$ violates the constraint, i.e.:

$$
\frac{W_{j}-3 t+W_{0}}{2}-W_{0}<W_{0}-Z_{i}^{*}
$$

which can be rewritten:

$$
W_{j}<3 t+3 W_{0}-2 Z_{i}^{*}
$$

Taking the sum of inequalities (23) and (25) above, we obtain:

$$
W_{i}+W_{j}<6 t+2 W_{0}
$$

We can then write the fact that the constraint in (21) is binding, $\Pi_{a d v}\left(Z_{i}^{*}, W_{i}\right)=\widehat{\Pi}_{a d v}\left(W_{j}, \Pi_{l}\left(Z_{i}^{*}\right)\right)$, as:

$$
\frac{\left(W_{i}-Z_{i}^{*}\right)}{2 t}\left(t+\frac{Z_{i}^{*}-W_{0}}{3}\right)=\frac{\left(W_{j}-Z_{j}^{*}\right)}{2 t}\left(t+\frac{Z_{j}^{*}-W_{0}}{3}\right),
$$

which, after using (24) and re-arranging, is equivalent to:

$$
t\left(W_{i}-W_{j}-Z_{i}^{*}+Z_{j}^{*}\right)+\frac{Z_{i}^{*}-W_{0}}{3}\left(W_{i}+W_{j}-Z_{i}^{*}-Z_{j}^{*}\right)=0
$$

Using (24) again, this is equivalent to:

$$
t\left(W_{i}-W_{j}\right)+\frac{Z_{i}^{*}-W_{0}}{3}\left(W_{i}+W_{j}-2 W_{0}-6 t\right)=0
$$

But (26) implies $W_{i}+W_{j}-2 W_{0}-6 t<0$ and we must have $Z_{i}^{*}-W_{0} \geq 0$ (otherwise platform $i$ would prefer to not provide any advertising in stage 4$)$. Thus, we conclude that $W_{i}-W_{j} \geq 0$.

Suppose platform A wins the advertiser in equilibrium. Then the lemma implies $X\left(s_{A}, \pi\right)+$ $V\left(s_{A}\right) \geq X\left(s_{B}, \pi\right)+V\left(s_{B}\right)$ and platform A's profit in stage 2 is $\Pi_{A}\left(s_{A}, s_{B}\right)=\Pi_{w}\left(Z_{A}^{*}\right)$, where 
$Z_{A}^{*}$ solves:

$$
\begin{gathered}
Z_{A}^{*}=\arg \max _{Z_{A}}\left\{\frac{1}{2 t}\left(t+\frac{Z_{A}-W_{0}}{3}\right)^{2}\right\} \text { s.t. } \frac{\left(W_{A}-Z_{A}\right)}{2 t}\left(t+\frac{Z_{A}-W_{0}}{3}\right) \geq \widehat{\Pi}_{a d v}\left(W_{B}, Z_{A}^{*}\right) \\
\widehat{\Pi}_{a d v}\left(W_{B}, Z_{A}^{*}\right) \equiv \max _{Z_{B}}\left\{\frac{\left(W_{B}-Z_{B}\right)}{2 t}\left(t+\frac{Z_{B}-W_{0}}{3}\right)\right\} \text { s.t. } \frac{1}{2 t}\left(t+\frac{Z_{B}-W_{0}}{3}\right)^{2} \geq \frac{1}{2 t}\left(t+\frac{W_{0}-Z_{A}^{*}}{3}\right)^{2}
\end{gathered}
$$

Suppose there exists $s_{A}^{\prime}$ such that $X\left(s_{A}^{\prime}, \pi\right)+V\left(s_{A}^{\prime}\right)>X\left(s_{A}, \pi\right)+V\left(s_{A}\right)$, which implies $X\left(s_{A}^{\prime}, \pi\right)+V\left(s_{A}^{\prime}\right)>X\left(s_{B}, \pi\right)+V\left(s_{B}\right)$. Thus, if platform A deviates to $s_{A}^{\prime}$ in stage 1 then the lemma above implies that platform $\mathrm{A}$ wins the advertiser in stage 2 with probability 1 . Let then $\Pi_{A}\left(s_{A}^{\prime}, s_{B}\right)=\Pi_{w}\left(Z_{A}^{* \prime}\right)$, where $Z_{A}^{* \prime}$ is defined similarly to $Z_{A}^{*}$, except that $W_{A}$ is replaced by $W_{A}^{\prime} \equiv X\left(s_{A}^{\prime}, \pi\right)+V\left(s_{A}^{\prime}\right)$.

There are several possibilities. First suppose the constraint in the definition of $\widehat{\Pi}_{a d v}\left(W_{B}, Z_{A}^{*}\right)$ is not binding, i.e.

$$
\widehat{\Pi}_{a d v}\left(W_{B}, Z_{A}^{*}\right)=\frac{1}{24 t}\left(3 t+W_{B}-W_{0}\right)^{2},
$$

which does not depend on $Z_{A}^{*}$. Pick then any $\varepsilon$ such that $0<\varepsilon<W_{A}^{\prime}-W_{A}$. We have $Z_{A}^{* \prime} \geq$ $Z_{A}^{*}+\varepsilon>Z_{A}^{*}$. To see this, note that $\frac{1}{2 t}\left(t+\frac{Z_{A}-W_{0}}{3}\right)^{2}$ is increasing in $Z_{A}$ and:

$$
\begin{aligned}
\frac{\left(W_{A}^{\prime}-Z_{A}^{*}-\varepsilon\right)}{2 t}\left(t+\frac{Z_{A}^{*}+\varepsilon-W_{0}}{3}\right) & >\frac{\left(W_{A}-Z_{A}^{*}\right)}{2 t}\left(t+\frac{Z_{A}^{*}-W_{0}}{3}\right) \\
& =\widehat{\Pi}_{a d v}\left(W_{B}, Z_{A}^{*}\right)=\widehat{\Pi}_{a d v}\left(W_{B}, Z_{A}^{*}+\varepsilon\right)
\end{aligned}
$$

where the last equality follows from the fact that $\frac{1}{2 t}\left(t+\frac{W_{0}-Z_{A}^{*}}{3}\right)^{2}$ is decreasing in $Z_{A}^{*}$.

Second, suppose the constraint in the definition of $\widehat{\Pi}_{A}\left(W_{B}, Z_{A}^{*}\right)$ is binding, which implies

$$
Z_{B}^{*}-W_{0}=W_{0}-Z_{A}^{*}
$$

and

$$
\begin{aligned}
& Z_{A}^{*}=\arg \max _{Z_{A}}\left\{\frac{1}{2 t}\left(t+\frac{Z_{A}-W_{0}}{3}\right)^{2}\right\} \\
& \text { s.t. } \frac{\left(W_{A}-Z_{A}\right)}{2 t}\left(t+\frac{Z_{A}-W_{0}}{3}\right) \geq \frac{\left(W_{B}-2 W_{0}+Z_{A}^{*}\right)}{2 t}\left(t+\frac{W_{0}-Z_{A}^{*}}{3}\right)
\end{aligned}
$$

There are now two possibilities regarding $Z_{A}^{* \prime}$ : 
- If the constraint in the definition of $\widehat{\Pi}_{a d v}\left(W_{B}, Z_{A}^{* \prime}\right)$ is also binding then we have:

$$
\begin{aligned}
& Z_{A}^{* \prime}=\arg \max _{Z_{A}}\left\{\frac{1}{2 t}\left(t+\frac{Z_{A}-W_{0}}{3}\right)^{2}\right\} \\
& \text { s.t. } \frac{\left(W_{A}^{\prime}-Z_{A}\right)}{2 t}\left(t+\frac{Z_{A}-W_{0}}{3}\right) \geq \frac{\left(W_{B}-2 W_{0}+Z_{A}^{* \prime}\right)}{2 t}\left(t+\frac{W_{0}-Z_{A}^{* \prime}}{3}\right)
\end{aligned}
$$

Comparing (27) and (28), the only difference is $W_{A}^{\prime}>W_{A}$, so $Z_{A}^{* \prime}>Z_{A}^{*}$.

- If the constraint in the definition of $\widehat{\Pi}_{a d v}\left(W_{B}, Z_{A}^{* \prime}\right)$ is not binding then:

$$
\frac{W_{B}-3 t+W_{0}}{2}-W_{0} \geq W_{0}-Z_{A}^{* \prime}
$$

and, since the constraint in the definition of $\widehat{\Pi}_{a d v}\left(W_{B}, Z_{A}^{*}\right)$ is binding, we also have:

$$
\frac{W_{B}-3 t+W_{0}}{2}-W_{0}<W_{0}-Z_{A}^{*}
$$

The last two inequalities imply $Z_{A}^{* \prime}>Z_{A}^{*}$.

Thus, in all possible cases, we have $Z_{A}^{* \prime}>Z_{A}^{*}$, which means that $s_{A}^{\prime}$ is a profitable deviation for platform A: $\Pi_{A}\left(s_{A}^{\prime}, s_{B}\right)>\Pi_{A}\left(s_{A}^{\prime}, s_{B}\right)$. Therefore, it must be that in the stage 1 equilibrium $s_{A}=s_{X+V} \equiv \arg \max _{s}\{X(s, \pi)+V(s)\}$.

If $s_{B} \neq s_{X+V}$ then platform B makes profits $\frac{1}{2 t}\left(t+\frac{W_{0}-Z_{A}^{*}}{3}\right)^{2}$ with probability 1 .

If $s_{2 B}=s_{A}=s_{X+V}$ then:

- with probability $1 / 2$ platform 1 wins the advertiser so platform B's profits are still $\Pi_{0}$

- with probability $1 / 2$ platform $\mathrm{B}$ wins the advertiser so its profits are $\Pi_{w}\left(s_{X+V}, s_{X+V}\right) \geq \Pi_{0}$ (the inequality is strict if the constraint in program 20 is not binding).

Thus, in all cases it is an equilibrium for platform B to also choose $s_{B}=s_{X+V}$ (this is the only equilibrium if the constraint in program 20 is not binding). 